\title{
IDEIAS DE MÚSICA NO CORO INFANTIL: POR QUE E PARA QUEM AS CRIANÇAS CANTAM?
}

\author{
Musical ideas in children's choirs: why and \\ who do they sing to?
}

\author{
Ideas musicales en el coro de niños: ¿por qué \\ y para quién cantan los niños?
}

Dhemy Fernando VIEIRA BRITO
Universidade do Minho
dhemy.brito@gmail.com

Viviane BeineKe

Universidade do Estado de Santa Catarina viviane.beineke@udesc.br

\begin{abstract}
Resumo: A pesquisa focaliza as perspectivas de crianças na educação musical, com o objetivo de compreender de que maneira elas se relacionam com a música e como elaboram e compartilham suas ideias de música, no contexto de um coro infantil. O referencial foi construído a partir de estudos que buscam compreender os sentidos atribuídos pelas crianças às suas práticas musicais, a partir da expressão ideias de música (Beineke, 2009, 2011; Brito, 2007, 2009; Santos, 2006). O estudo foi realizado com 29 crianças, entre 6 e 11 anos de idade, participantes do Cantoria - projeto de extensão do Colégio de Aplicação-UFSC, da cidade de Florianópolis (SC). O desenho metodológico incluiu: 1) observação e registro em áudio e vídeo dos ensaios do grupo; 2) produção de registro pelas crianças em cadernos individuais intitulados "Diários de ideias de música"; e 3) rodas de conversa, focalizando a prática coral e os registros nos diários. Os resultados do estudo apontam para as ideias de música das crianças construídas socialmente em suas relações com seus pares e com os professores, apresentando suas perspectivas em relação ao ser artista, suas concepções sobre as apresentações musicais, suas ideias sobre repertório e o brincar nos encontros do grupo. Acredita-se que pesquisas dessa natureza contribuam para o fortalecimento de práticas musicais mais participativas, identificando e valorizando as compreensões das crianças nos processos de construção musical.
\end{abstract}

Palavras-chave: Coro infantil. Ideias de música. Pesquisa com crianças.

\begin{abstract}
The research focuses on children's perspectives on music education, with the aim of understanding how they relate to music and how they develop and share their ideas of music, in the context of a children's choir. The development of the theoretical framework was based in studies that seek to understand the meanings attributed by children to their musical practices, based on the expression of music ideas (Beineke, 2009, 2011; Brito, 2007, 2009; Santos, 2006). The research was conducted with 29 children, between 6 and 11 years old, from Cantoria - a children's choir of College of Aplication-UFSC, Florianopolis city. The methodological design includes: 1) observation and audio and video recording of children's choir rehearsals; 2) recording of data by children in individual notebooks entitled "Diary of ideas on music"; and 3) rounds of conversation, focusing on choral practice and diary entries. The results of the study reveal the ideas of music socially constructed children in their relationships with their peers and teachers, presenting their perspectives on being an artist, their conceptions about musical performances, their ideas on the choice of repertoire and the presence of playing in group meetings. Research of this nature is believed to contribute to the strengthening of more participatory musical practices, identifying and valuing children's understandings in the processes of musical construction.
\end{abstract}

Keywords: Children's choir. Ideas on music. Research with children. 


\begin{abstract}
Resumen: La investigación se centra en las perspectivas de los niños sobre la educación musical, con el objetivo de comprender cómo se relacionan con la música y cómo desarrollan y comparten sus ideas sobre la música, en el contexto de un coro infantil. El marco se construyó a partir de estudios que buscan comprender los significados que los niños atribuyen a sus prácticas musicales, a partir de la expresión de ideas musicales (Beineke, 2009, 2011; Brito, 2007, 2009; Santos, 2006). El estudio se realizó con 29 niños, entre 6 y 11 años, participantes en Cantoria-proyecto de extensión del Colégio de Aplicação-UFSC, en la ciudad de Florianópolis (SC). El diseño metodológico incluyó: 1) observación y grabación en audio e video de los ensayos del grupo; 2) producción de registros por parte de los niños en cuadernos individuales, titulados "Diarios de ideas musicales"; y 3) círculos de conversación, enfocándose en la práctica coral y registros diarios. Los resultados del estudio apuntan a las ideas musicales de los niños construidas socialmente en sus relaciones con sus compañeros y profesores, presentando sus perspectivas en relación al ser artista, sus concepciones sobre las interpretaciones musicales, sus ideas sobre el repertorio y la interpretación en reuniones de grupo. Se cree que investigaciones de esta naturaleza contribuyen al fortalecimiento de práticas musicales más participativas, identificando y valorando las comprensiones de los niños en los procesos de construcción musical.
\end{abstract}

Palabras clave: Coro infantil. Ideas musicales. Investigación con niños.

\title{
INTRODUÇÃO
}

A compreensão sobre como as crianças atribuem sentido e compartilham suas ideias musicais tem sido progressivamente valorizada na área de educação musical. Nesse tema, vem sendo utilizadas diferentes definições e abordagens, como significados da música (Anders, 2014), sentidos e significados (Rhoden, 2010), concepções de música (Ponso, 2010), narrativas das crianças (Marques, 2016; Marques; Abreu, 2018; Pedrini, 2013) e ideias de música (Beineke, 2009, 2011; Brito, 2007, 2009; Santos, 2006).

Esses estudos analisam a importância de ouvir as crianças, valorizar seus olhares e proporcionar um ambiente que possibilite a expressão e a reflexão de suas ideias, provocando novas compreensões sobre como elas aprendem e se conectam com a música. Focalizando o contexto de um coro infantil, este artigo se propõe a refletir sobre a maneira como as crianças se relacionam com a música e como elaboram e compartilham suas ideias de música.

A partir de uma pesquisa com crianças, o estudo ${ }^{1}$ teve como objetivo compreender de que maneira elas se relacionam com a música e como elaboram e compartilham suas ideias de música, no contexto de um coro infantil. A pesquisa foi realizada com um grupo de 29 crianças do Cantoria - projeto de extensão do Colégio de Aplicação-UFSC, que busca oferecer práticas educativas de iniciação musical através do canto coral. Os resultados deste estudo revelam as ideias de música construídas socialmente, a partir de relações com seus pares e professores, apresentando perspectivas em relação ao ser artista, concepções sobre apresentações musicais, ideias de escolha de repertório e o brincar nos encontros do coro infantil.

\footnotetext{
1 Este artigo apresenta os resultados de uma pesquisa de mestrado concluída, desenvolvida no Programa de Pós-Graduação em Música da Universidade do Estado de Santa Catarina (Udesc), sob orientação da Profa Dra Viviane Beineke. A pesquisa foi realizada com apoio da Coordenação de Aperfeiçoamento de Pessoal de Nível Superior (Capes) - Código de Financiamento 001.
} 


\section{AS CRIANÇAS E SUAS IDEIAS DE MÚSICA}

Inicialmente utilizada por Santos (2006), a expressão ideias de música questiona paradigmas predefinidos ao longo do século XX, sobre os limites entre música e não música. Para a autora, ideias de música compreende os significados atribuídos ao fazer musical, buscando ressonância em uma imagem de mundo do indivíduo, oportunizando novas poéticas musicais. Ancorada em Gilles Deleuze e Félix Guattari, Santos (2006) realizou uma pesquisa com crianças entre 8 e 11 anos de idade, propondo pensar e desenvolver uma proposta de criação musical que não apenas elencasse sons, mas que, sobretudo, determinasse a função de uma escuta que compõe a amplitude de uma ideia de música. Diante de questões como isso é música ou como é essa música, as crianças revelaram, por meio de falas e desenhos, aspectos relacionados ao seu imaginário ou de um ideal sonoro do ambiente. "Foi levado em conta o fato de as crianças terem desenhado muitos passarinhos, galos e cachorros e terem falado muito dos sons produzidos por eles" (Santos, 2006, p. 111). As representações dos sons realizadas pelas crianças oportunizaram "um alargamento da sua ideia de música", estabelecidas a partir da movimentação, curiosidade e da imaginação de cada criança (Santos, 2006).

Sobre a singularidade do fazer musical com crianças que emerge em ambientes educacionais marcados por modos de comunicação, Brito (2007) cartografou possibilidades e significados acerca das relações do ser humano com os sons e com a música, desenvolvendo uma pesquisa com crianças de uma oficina de música. Estabelecendo relações com o sonoro e o musical no curso da infância, a autora infere que as ideias de música infantis refletem a importância e o papel da música na vida humana, a partir de múltiplas perspectivas. Essas ideias de música são estabelecidas a partir da diversidade da natureza de trocas, presentes nos signos representativos, intelectuais e principalmente nos dispositivos de afetos (Brito, 2007).

Processos de interação entre as crianças também foram discutidos na pesquisa de Beineke (2009), ao analisar os processos intersubjetivos presentes na composição musical com crianças. O conceito ideias de música foi utilizado como dispositivo para a compreensão das perspectivas infantis sobre suas composições. Foi a partir da observação das aulas e dos diálogos com as crianças que Beineke (2009) analisou as ideias de música reveladas nas atividades de composição, como: 1) a produção musical com e para outras pessoas; 2) o planejamento das músicas; 3) a participação e o engajamento das crianças nas composições; e 4) a indissociabilidade entre o compor e o tocar. Como destaca a autora, foram os diálogos entre as crianças que acionaram a atualização, a transformação e a ampliação de suas ideias de música, o que favoreceu a aprendizagem criativa do grupo (Beineke, 2009).

A partir do conceito ideias de música, outras pesquisas vêm sendo desenvolvidas na última década, sobretudo no campo da aprendizagem criativa e em diferentes contextos, como oficinas de música (Oliveira, 2015; Pinheiro Machado, 2013; Roncale, 2017), escola básica (Visnadi, 2013) e grupo de terceira idade (Fujimoto, 2015). Além disso, é importante destacar que esses 
trabalhos estão vinculados ao Programa de Pós-Graduação em Música da Udesc e refletem a construção de um corpo de conhecimento científico no campo das criatividades em educação musical.

Unindo-se a essa constelação de pesquisas, o presente estudo foi realizado no contexto de um coro infantil, buscando compreender de que maneira as crianças se relacionam com música e como elaboram e compartilham suas ideias de música.

\section{PESQUISA COM CRIANÇAS: CONSTRUINDO UM CAMINHO METODOLÓGICO}

A realização desta pesquisa provocou a elaboração de um desenho metodológico que permitisse compreender as subjetividades das crianças sobre suas práticas corais, bem como suas visões de si e do mundo. De acordo com Denzin e Lincoln (2006), essas são características essenciais dos estudos qualitativos, baseando-se em interpretações dos acontecimentos e das relações do ser humano consigo e com o que o rodeia. Nesse sentido, o estudo qualitativo "consiste em um conjunto de práticas materiais e interpretativas que dão visibilidade ao mundo" (Denzin; Lincoln, 2006, p. 17).

$\mathrm{Na}$ realização deste estudo, assumimos uma investigação com crianças, buscando a participação infantil nos processos de produção de dados e entendendo-a como contribuição para a construção conjunta de ideias. É nessa perspectiva que se estabelece uma construção coletiva de aprendizado, entre pesquisadores, professores e alunos, transformando as crianças em aprendizes e ensinantes (Prado, 2011).

Como protagonistas, as crianças, juntamente com as professoras, são as que entram em cena em um tempo e em um espaço de se viver as infâncias, múltiplas, diversas, personagens das brincadeiras, festivas, afetivas, observadoras, ruidosas, silenciosas, inovadoras, inventivas e também reprodutoras. Aprendizes e ensinantes (Prado, 2011, p. 112).

Nesse paradigma investigativo, o objetivo principal está em criar um ambiente e um processo em que o conhecimento vinculado ao contexto favoreça a participação das crianças, não apenas ouvindo suas vozes, mas oportunizando técnicas que minimizem a hegemonia entre investigadores e sujeitos da pesquisa. "Surge a iniciativa de colocar a criança como efetivo sujeito da pesquisa científica e, ainda, a valorização do registro de expressões tipicamente infantis" (Rodrigues; Borges; Silva, 2014, p. 273). É nesse sentido que se analisa a importância de ambientes e técnicas de produção de dados com as crianças, enfatizando a compreensão dos seus modos de pensar e agir.

Com base nos questionamentos suscitados, destacamos que tais iniciativas fortalecem o campo dos estudos da infância, refletindo sobre ambientes de pesquisa inclusivos no que tange à participação infantil. Nesse processo de compreensão das crianças enquanto sujeitos plenos de direitos e capazes 
de contribuir para o conhecimento científico, as técnicas de produção de dados foram elaboradas com o fito de fomentar perspectivas das crianças em torno do tema. Além disso, torna-se importante destacar que alguns procedimentos éticos foram indispensáveis na realização desta pesquisa com as crianças.

A decisão de pesquisar o Cantoria, projeto de extensão do Colégio de Aplicação-UFSC, da cidade de Florianópolis (SC), ocorreu no final do primeiro semestre de 2018, quando foram estudados os procedimentos e cuidados éticos necessários ao desenvolvimento de pesquisas com crianças. O projeto foi submetido à Plataforma Brasil, vinculada à Comissão Nacional de Ética em Pesquisa. ${ }^{2}$ Após a aprovação e deliberação do início da pesquisa pelo Comitê de Ética da Udesc, a pesquisa foi apresentada às crianças, professores, pais e responsáveis, que receberam os termos de consentimento livre e esclarecido, consentimento para vídeos, fotografias e gravações e o termo de assentimento para as crianças. Cumpridas as exigências legais aprovadas pelo Comitê de Ética, foram iniciadas as etapas de produção de dados da pesquisa, as quais incluíram: 1) observação e registro em áudio e vídeo dos ensaios do coro infantil; 2) produção de registro pelas crianças em cadernos individuais, intitulados "Diários de ideias de música"; e 3) rodas de conversa (RC), focalizando a prática coral e o registro nos diários.

A investigação foi realizada com 29 crianças, entre 6 e 11 anos de idade, orientadas por dois professores formados em música. A atividade de extensão oportuniza práticas educativas de iniciação musical através do canto coletivo, direcionada a alunos da escola e outras crianças da região. Foram observados 13 encontros, além de duas apresentações do coro. Os primeiros contatos com o grupo foram realizados ao final do primeiro semestre de 2018, com o intuito de perceber as relações estabelecidas nos ensaios, a estrutura do projeto de extensão, conhecer as crianças participantes e as dinâmicas estabelecidas nos encontros do coro. Esse primeiro momento de observação oportunizou identificar as relações estabelecidas entre as próprias crianças e entre elas e os professores.

Como destacam Martins Filho e Barbosa (2010, p. 23-24), é na observação que "pesquisados e pesquisadores vão pouco a pouco estabelecendo e criando laços, o que favorece as relações e o desenvolvimento de uma participação sensivel às produções das crianças". Essa técnica nos permitiu uma aproximação à realidade do grupo, auxiliando a compreensão posterior das ideias das crianças registradas nos diários e expressadas nas rodas de conversa.

\footnotetext{
2 O Parecer Consubstanciado do CEP pode ser localizado pelo número do CAAE 96024118.4.0000.0118. Os termos de consentimento e assentimento foram entregues em duas vias, solicitando a autorização dos responsáveis para a participação das crianças na pesquisa, incluindo o uso de gravação em áudio e vídeo, a produção das crianças nos "Diários de ideias de música", as entrevistas com as crianças e a utilização dos dados produzidos para fins de publicação em meio acadêmico-científico.
} 
Como segunda etapa da produção dos dados, entregamos às crianças um diário onde elas pudessem registrar livremente os sentidos atribuídos à prática coral que gostariam de compartilhar conosco, enquanto pesquisadores. Essa ferramenta teve por objetivo oportunizar que elas registrassem suas ideias em forma de desenho, colagem, anotações, etc. Essa etapa foi conduzida seguindo indicações de Sarmento (2011), que recomenda a utilização de metodologias que permitam às crianças a utilização de expressões tipicamente infantis, assim como o desenho infantil. De acordo com o autor, "o desenho é especialmente apropriado para aceder a formas de expressão de crianças pequenas” (Sarmento, 2011, p. 53).

Poder acompanhar o acto de elaboração do desenho ou captar as opiniões expressas pelas crianças sobre as suas próprias produções plásticas pode contribuir para uma maior compreensão dos significados atribuídos e fazer convergir dois registos simbólicos, aliás nem sempre coincidentes. O desenho e a fala são coconstitutivos de um modo de expressão infantil cujas regras não são as mesmas da expressão adulta (Sarmento, 2011, p. 53).

A partir da produção das crianças nos "Diários de ideias de música", foram realizadas seis rodas de conversa ( $\mathrm{RC} 1, \mathrm{RC} 2$, etc.) com grupos de quatro a cinco crianças, no intuito de dialogar sobre suas produções e suas ideias em relação à prática coral infantil. Destacamos a importância da triangulação das técnicas de produção dos dados, o que nos permitiu compreensão mais contextualizada das ideias de música das crianças.

Durante todo o período da produção dos dados, os relatórios e os registros transcritos (áudio e vídeo) foram organizados e separados por data dos encontros, sendo identificados e catalogados por data da observação e das rodas de conversa realizadas com as crianças. Posteriormente, os dados foram analisados observando as temáticas encontradas tanto nos relatórios quanto nos registros, assinalando a frequência com que aparecia cada assunto.

O próximo passo esteve em organizar as falas das crianças contidas nos relatórios escritos e nos registros em áudio e vídeo, também os dividindo por temáticas a fim de gerar novos arquivos para cada assunto. Além disso, juntamente com os relatórios e registros, foram organizadas as fotos registradas durante ensaios e apresentações do coro infantil.

Na organização dos dados, fomos aprofundando nossos olhares e estabelecendo algumas categorias de acordo com as falas das crianças e com base nas questões norteadoras, realizadas nas rodas de conversa. Estabelecendo categorias de análise, emergiram os temas relacionados às ideias das crianças sobre as apresentações musicais e ao ser artista, as ideias de escolha de repertório e sobre o brincar nos encontros do coro infantil, como apresentado a seguir. 


\section{IDEIAS SOBRE AS APRESENTAÇÕES: O SER ARTISTA E A PLATEIA}

A minha primeira apresentação foi no primeiro ano
e eu achei mágico.

Bia

Nas rodas de conversa, as crianças puderam dialogar sobre os ensaios do grupo, as apresentações, o repertório e as metodologias de ensino empregadas no coro. Os temas discutidos emergiram dos acontecimentos dos ensaios, das produções nos diários e das apresentações musicais. Dialogando sobre o tema apresentação, as crianças expressaram diferentes pontos de vista sobre como se sentiam, suas ideias sobre os locais das apresentações, como compreendem sua participação no coro infantil, os critérios para uma apresentação ser de verdade e a importância dessas apresentações como meio de compartilhar experiências musicais com seus pais e amigos.

As apresentações musicais do coro foram destacadas como espaços relevantes para as crianças, a partir de expressões como momento importante de apresentação e oportunidade de ser artista. Outro aspecto destacado pelas crianças esteve centrado nos lugares onde gostam de se apresentar, sendo este um dos assuntos representados em seus diários. Ao descrever o desenho que havia feito no diário, Lis e Bele reforçaram a necessidade da plateia numa apresentação do grupo musical, e ainda refletiram sobre o que acreditavam ser uma apresentação de verdade:

Pesquisador: $\mathrm{E}$ você acha que tem que ter plateia para a apresentação do coral?

Bele: Claro, né? Senão não é apresentação.

Lis: É. Tem que ter gente para assistir a gente cantando.

Pesquisador: $\mathrm{E}$ por que você desenhou eles embaixo?

Lis: Porque eles estão sentados assistindo a gente. Aí eles ficam nas cadeiras e a gente fica aqui em cima no palco. A gente tem que ficar em cima senão eles não conseguem ver a gente. E também porque todo artista tem que ficar em cima do palco, né? Pesquisador: E se não tiver palco? Aí não é apresentação?

Bele: Eu acho que não. Aí é tipo a gente só mostrando o que a gente faz, mas não é uma apresentação de verdade.

Lis: É verdade (RC4, p. 4-5).

Para Lis, a expressão de verdade se refere ao que ela considerava relevante para uma apresentação do coro infantil. Ilustrando sua ideia no papel, Lis desenhou palco, cortina e pessoas na plateia. $\mathrm{O}$ significado atribuído pela menina à expressão de verdade refere-se ao que algumas das crianças do Cantoria estabelecem como critérios para que uma apresentação seja boa ou ruim. Lis esclarece: "Eu acho que uma apresentação é boa quando a gente canta bem e quando os pais e os nossos amigos da escola batem bastante palmas para a gente." No decorrer das rodas de conversa, as crianças citaram outros fatores que caracterizariam uma apresentação como boa ou ruim: 
Luna: A apresentação é boa quando a professora elogia a gente depois (RC3, p. 2).

Nico: Eu acho que a apresentação é ruim quando a gente mesmo não gosta do que apresentou no palco (RC7, p. 1).

Jujuba: Quando todo mundo assovia e grita quando acaba a música. Aí eu sei que a apresentação foi muito legal (RC2, p. 5).

Carol: Na verdade, eu acho que quando os pais e os amigos vêm cumprimentar a gente no final da apresentação. Aí eu sei que a gente se apresentou bem $(\mathrm{RC} 2,6)$.

As falas das crianças mostraram que elas estabeleceram diferentes critérios de avaliação sobre as apresentações musicais, tendo como ponto em comum a importância de ver seus pais e amigos assistindo às apresentações. Refletindo sobre a ideia atribuída à apresentação do coro infantil em relação à presença dos pais e amigos, Bel declarou: "Eu amo quando posso mostrar para os outros o que o Cantoria sabe cantar. É bem legal ver meus pais e amigos nas apresentações." De acordo com as discussões em grupo, as apresentações musicais do coro foram analisadas como uma prática social, que tem sentido quando compartilhada com outras pessoas. Essa visão é conferida também por Pinheiro Machado (2013), ao analisar que as apresentações ampliam as experiências musicais e as ideias de música das crianças, por entender que a música tem sentido quando compartilhada com outras pessoas.

Além disso, outro aspecto importante refletido pelas crianças foi a reação dos pais e amigos sobre o repertório musical realizado nas apresentações. Ideias sobre as letras das canções, preferências musicais e o que a plateia gostaria ou não de ouvir foram destacadas pelas crianças nas rodas de conversa.

\section{IDEIAS SOBRE O REPERTÓRIO: COMO SELECIONAR?}

Seria legal, também, cantarmos o que a gente gosta. Acho que nos motivaria mais nos ensaios.

Bele

Desde os primeiros encontros nas rodas de conversa, foi possivel observar a importância dada pelas crianças aos debates sobre o repertório do grupo Cantoria. Nesses diálogos, as crianças relacionaram o repertório executado pelo grupo com as músicas apreciadas no dia a dia, e as músicas compartilhadas com seus pais e amigos. Sobre suas bandas e artistas preferidos, a ideia de um repertório baseado nas preferências musicais foi contraposta à concepção das crianças sobre música infantil. Nos questionamentos emergidos, as crianças apresentaram grande diversidade nas ideias sobre o repertório. Refletindo sobre quais músicas deveriam cantar, Vivi questionou seus 
colegas: "Será que o público iria gostar das nossas músicas?" Então elas iniciaram uma discussão sobre os critérios para a seleção do repertório executado pelo coro: seria mais importante considerar as suas próprias preferências musicais ou as do público?

Lipe: Minha mãe ia adorar Queen no Coral.

Pesquisador: E você, Vivi? Você acha que não? Por que você acha que eles não iriam gostar?

Vivi: Porque minha mãe odeia essas músicas.

Pesquisador: Mas quem é que tem que gostar das músicas que vocês cantam?

Angel: A gente.

Vivi: O público.

Angel: Não, a gente.

Vivi: A minha mãe ficaria uma fúria comigo (RC6, p. 6).

As falas das crianças denotam uma preocupação quanto à aprovação dos pais em relação ao repertório do coro infantil. Esse foi o caso de Lipe e Vivi, quando destacaram a percepção de suas mães sobre as músicas cantadas pelo grupo. Embora tenham essa preocupação, as crianças discutiram sobre a importância de se pensar um repertório que não fosse tão infantil, mas que apresentasse canções familiares aos pais e colegas:

Angel: Eu acho que eles iam gostar, porque todas as crianças da minha sala amam cantores famosos. Daí, Galinha Pintadinha ${ }^{3} \ldots$ ninguém vai gostar. E também...

Vivi: Patati Patatá. ${ }^{4}$

Angel: Isso. Só as criancinhas muito petitiquinhas iriam gostar. A nossa sala mesmo ia gostar das nossas músicas [referindo-se às músicas que elas escutam no dia a dia], porque são músicas que todas elas gostam (RC6, p. 6).

O diálogo das crianças revelou suas ideias sobre quais músicas elas considerariam apropriadas à sua faixa etária e o que deveria ser executado pelo grupo, ressaltando a idade dos participantes do coro infantil. "Eu acho que a maioria aqui do nosso coral tem quase dez anos. É muito chato ficar cantando musiquinhas de bebezinhos, mas a gente também não pode cantar músicas de adultos porque o público também vai achar estranho" (Vivi, RC6, p. 5). Nesse sentido, percebemos que as crianças do Cantoria estão ativamente envolvidas com as decisões que são tomadas em relação às suas práticas musicais no coro. Além de elas colocarem em debate os seus entendimentos sobre o que é música de adulto ou música de criança, elas também estão construindo coletivamente suas ideias sobre as conexões que se estabelecem entre os artistas e seu público.

\footnotetext{
3 Animação produzida através de videoclipe, com conteúdo direcionado ao público infantil.

4 Fundada em 1995, a dupla brasileira de palhaços de circo já apresentou programas televisivos infantis, com o objetivo de entretenimento através de músicas e videoclipes.
} 
Dialogando com seus colegas, Lipe levantou outra questão sobre o repertório do coro: "Por que não poderíamos cantar as músicas que a gente ouve no YouTube?" (RC6, p. 6). A pergunta de Lipe fez com que algumas crianças na roda de conversa ficassem em silêncio por alguns instantes, refletindo sobre uma possivel resposta. Após alguns segundos de reflexão, Lara disse que, na sua opinião, "as músicas do YouTube poderiam ser legais e, ao mesmo tempo, agradaria $[\mathrm{m}]$ nossos pais e colegas do colégio" (RC6, p. 6). As falas das crianças ao relacionarem suas ideias sobre o repertório do coro infantil foram, em sua maioria, relacionadas à aprovação dos pais e amigos da escola. Essa ideia caminha no sentido percebido por Brito (2007), quanto destaca que a experiência musical tem sentido para as crianças quando celebrada, vivida e convivida com outras pessoas.

\section{IDEIAS SOBRE O BRINCAR E A IMAGINAÇÃO: DIVERSÃO E APRENDIZAGEM}

\section{Nesses momentos a gente se diverte, brinca com os amigos e aprende, tudo ao mesmo tempo.}

Flor

Pensando sobre as atividades que envolveram jogos e brincadeiras nos ensaios do coro infantil, as crianças enfatizaram que esses momentos deixaram o encontro mais divertido, animado, legal, especial e mágico:

Bia: Deixa o ensaio muito mais divertido porque motiva mais quando a gente está brincando, e é um negócio que você se interessa mais (RC5, p. 6).

Mari: Aqui é um lugar onde a gente pode cantar músicas e fazer brincadeiras (RC1, p. 3).

Pipo: O ensaio fica muito mais legal quando a professora coloca umas brincadeiras (RC3, p. 4).

As falas revelam o prazer de experimentar as novas brincadeiras propostas pela professora, como, por exemplo, quando realizavam atividades de técnica vocal propostas no ensaio.

Vivi: Eu acho que as brincadeiras são bem divertidas.

Pesquisador: Por quê?

Vivi: Porque às vezes elas enrolam a nossa língua [risos], e são bem dificeis de aprender.

Pesquisador: Ah, então são desafios?

Flor: Eu acho que, quando a professora coloca essas brincadeiras e esses desafios nos ensaios, nesses momentos a gente se diverte, brinca com os amigos e aprende, tudo ao mesmo tempo (RC6, p. 2-3). 
A partir do diálogo exposto, observou-se que a novidade e a curiosidade estiveram presentes na proposição de novos desafios, que foram considerados como brincadeiras pelas crianças. Tal como analisa Oliveira (2015), os jogos e brincadeiras propiciam diversão, permitindo que as crianças se envolvam com desafios, interajam e trabalhem coletivamente. Além disso, foi possivel perceber que o conceito do brincar não esteve ligado, somente, às brincadeiras e aos jogos, mas também à imaginação oportunizada nos encontros. Segundo Angel, a movimentação do corpo durante os exercícios vocais estimulou sua criatividade e sua imaginação em meio às atividades:

Pesquisador: Em relação às brincadeiras que a professora colocou nos ensaios, o que vocês acharam?

Lipe: Eu gosto muito porque é um momento que a gente pode se divertir bastante.

Angel: Eu também gosto. Principalmente quando a professora fala "vamos cantar como se fossem bailarinos" ou "pensem a nota voando no espaço". Ai a gente fica imaginando essas coisas que ela falou e vamos fazendo gestos. Eu acho que a voz fica até mais bonita (RC6, p. 2).

Os dados analisados fornecem algumas pistas sobre como as crianças idealizam as atividades que podem ser desenvolvidas na prática coral infantil. As brincadeiras, incluindo atividades que favoreçam a imaginação, gestos e movimentos, aparecem como componente importante no ensaio, contribuindo para a dinâmica e a interação entre elas nos ensaios do coro. Refletindo sobre a imaginação das crianças nos processos de ensino-aprendizagem, Craft, Jeffrey e Leibling (2001) ressaltam que esse mecanismo se apresenta como um dos fatores da aprendizagem criativa, aliado à experimentação, à inovação, à expressão, à invenção, à reflexão e à valorização de si e de suas ideias.

Em relação às ideias sobre o brincar nos ensaios do coro, as crianças expuseram suas perspectivas, relacionando-as como um momento disparador de prazer e alegria, permitindo o desenvolvimento da imaginação. Além disso, o compartilhamento das ideias de música das crianças sobre o brincar nos ensaios permitiu que elas ampliassem seus entendimentos, visando construir uma prática coral mais participativa, dinâmica e interativa.

\section{POR QUE E PARA QUEM CANTAMOS?}

Compreender as ideias de música das crianças a respeito de suas práticas musicais em coros infantis é essencial quando pretendemos realizar um trabalho em educação musical baseado num paradigma participativo, que valorize os interesses das crianças e incentive aprendizagens colaborativas em que os seus questionamentos e reflexões fazem parte do jogo, isto é, do planejamento do professor e das dinâmicas que movimentam os ensaios e apresentações.

Neste artigo, diante das análises construídas a partir das perspectivas das crianças, compreendemos que suas ideias de música estiveram permeadas 
pelo questionamento: por que e para quem cantamos no coro infantil?. Além disso, observamos que as crianças se sentiram motivadas a compartilhar as suas ideias de música sobre a prática coral infantil, indo além das questões apresentadas nas rodas de conversa, dialogando com seus colegas de grupo.

Sobre as apresentações, percebemos que as crianças consideram diferentes pontos de vista quando discutem sobre a importância de compartilhar com um público específico o que elas desenvolvem durante os ensaios do grupo musical. Elas mostraram-se exigentes quanto ao local das apresentações musicais, ideias que estão ligadas às suas compreensões sobre o ser artista. Nesse sentido, podemos compreender o valor atribuído pelas crianças às apresentações do coro infantil, entendendo suas preocupações e questionamentos ao refletir sobre as expectativas da plateia, sobretudo seus pais e colegas de escola.

Ainda sobre o aspecto do que é direcionado musicalmente ao público, as crianças compartilharam ideias nas rodas de conversa sobre o repertório executado pelo grupo, evidenciando suas preocupações na dúvida entre as próprias preferências musicais e o que a plateia gostaria de ouvir do coro infantil. Nas rodas de conversa elas discutiram sobre critérios que poderiam orientar suas escolhas, considerando também o que elas identificam como música de adulto e música infantil. Constatamos que, de acordo com os diálogos das crianças, elas se colocam como críticos quando se trata do repertório a ser desenvolvido pelo grupo, tendo como guia a preocupação do para quem estamos cantando?

Outro aspecto analisado neste estudo esteve associado às atividades que envolveram o brincar nos ensaios do coro infantil. De acordo com as falas, observou-se a importância dada pelas crianças a esses momentos mais lúdicos, tornando o ensaio mais agradável quando as brincadeiras eram realizadas em conjunto. Ao dialogarem sobre as metodologias que envolviam brincadeiras nos ensaios, as crianças disseram que, para elas, "é um momento onde a gente pode fazer tudo junto. Brincar e aprender” (RC5, p. 4). Essa observação das crianças está intrinsicamente ligada à análise de Sarmento (2011, p. 51), ao destacar que "entre brincar e fazer coisas sérias não há distinção, sendo o brincar muito do que as crianças fazem de mais sério".

Ressaltamos que as variadas ideias de música das crianças denotaram valores e sentidos que elas atribuem à prática coral, tendo em vista que suas ideias de música são construídas socialmente, incluindo as relações estabelecidas com seus amigos, família, professores e o que elas veem na televisão. Pode-se assim compreender o fazer musical das crianças no coro infantil como prática social, uma vez que seus significados foram construídos socialmente, a partir de práticas musicais colaborativas.

Outro aspecto importante a se destacar neste estudo esteve no papel do professor e na importância de oportunizar espaços em que as crianças sejam ouvidas e valorizadas, refletindo sobre suas próprias ideias na prática coral infantil, contribuindo para a construção coletiva do fazer musical. E mais do que isso: não apenas ouvir a voz das crianças, mas ir além, considerando que elas podem contribuir com expressões e significados para uma prática 
musical mais participativa. Nesse sentido, a pesquisa salienta a importância de que regentes / professores de coros infantis dialoguem com as crianças para que os processos de trabalho musical considerem as aprendizagens entre as crianças, entendendo que suas ideias de música estão sempre em movimento.

Os resultados deste estudo apresentam contribuições que podem provocar o desenvolvimento de práticas corais infantis mais participativas, que reconheçam e valorizem as ideias de música das crianças. Por fim, ressaltamos que as ideias de música das crianças estão em constante transformação, sendo importante que educadores musicais estabeleçam uma relação dialógica com as crianças, a fim de proporcionar práticas musicais cada vez mais repletas de significado.

\section{REFERENCIAS}

ANDERS, Fernanda. Dançar na aula de música: "Dá gosto de vir para o colégio". 2014. Dissertação (Mestrado em Educação) - Faculdade de Educação, Universidade Federal do Rio Grande do Sul, Porto Alegre, 2014.

BEINEKE, Viviane. Processos intersubjetivos na composição musical de crianças: um estudo sobre aprendizagem criativa. 2009. Tese (Doutorado em Música) - Instituto de Artes, Universidade Federal do Rio Grande do Sul, Porto Alegre, 2009.

Aprendizagem criativa na escola: um olhar para a perspectiva das crianças sobre suas práticas musicais. Revista da Abem, Londrina, v. 19, n. 26, p. 92-104, jul./dez. 2011.

BRITO, Maria Teresa Alencar de. Por uma educação musical do pensamento: novas estratégias de comunicação. 2007. Tese (Doutorado em Comunicação e Semiótica) - Pontificia Universidade Católica de São Paulo, São Paulo, 2007.

Por uma educação musical do pensamento: educação musical menor. Revista da Abem, Porto Alegre, v. 21, p. 25-34, mar. 2009.

CRAFT, Anna; JEFFREY, Bob; LEIBLING, Mike. Creativity in education. London: A\&C Black, 2001.

DENZIN, Norman K.; LINCOLN, Yvonna S. Introdução: a disciplina e a prática da pesquisa qualitativa. In: DENZIN, Norman K.; LINCOLN, Yvonna S. (org.). O planejamento da pesquisa qualitativa: teorias e abordagens. Tradução Sandra Regina Netz. 2. ed. Porto Alegre: Artmed, 2006. p. 15-41.

FUJIMOTO, Tatiane Andressa da Cunha. Composição musical com idosos: re-arranjando a felicidade. 2015. Dissertação (Mestrado em Música) - Centro de Artes, Universidade do Estado de Santa Catarina, Florianópolis, 2015. 
MARQUES, Olivia Augusta Benevides. Pequenos enredos nas escolas parque de Brasília: o que contam as crianças sobre a aula de música. 2016. Dissertação (Mestrado em Música) - Instituto de Artes, Universidade de Brasília, Brasília, 2016.

MARQUES, Olivia Augusta Benevides; ABREU, Delmary Vasconcelos de. Pequenos enredos nas escolas parque de Brasília: o que contam as crianças sobre a aula de música. Revista da Abem, [s. l.], v. 26, n. 40, p. 131-148, jan./jun. 2018.

MARTINS FILHO, Altino José; BARBOSA, Maria Carmem Silveira. Metodologias de pesquisas com crianças. Revista Reflexão e Ação, Santa Cruz do Sul, v. 18, n. 2, p. 8-28, jul./dez. 2010.

OLIVEIRA, Andreia Pires Chinaglia de. "A gente ensina, aprende e inventa, tudo de uma vez": as aprendizagens colaborativas nas brincadeiras cantadas e jogos musicais numa oficina de música com crianças. 2015. Dissertação (Mestrado em Música) - Centro de Artes, Universidade do Estado de Santa Catarina, Florianópolis, 2015.

PEDRINI, Juliana Rigon. Sobre o aprendizado musical: um estudo de narrativas de crianças. 2013. Dissertação (Mestrado em Educação) Faculdade de Educação, Universidade Federal do Rio Grande do Sul, Porto Alegre, 2013.

PINHEIRO MACHADO, Cecília Marcon. "No nosso mundo a gente inventa": um estudo sobre a aprendizagem criativa em uma oficina de música para crianças. 2013. Dissertação (Mestrado em Música) - Centro de Artes, Universidade do Estado de Santa Catarina, Florianópolis, 2013.

PONSO, Caroline Cao. Música na escola: concepções de música das crianças no contexto escolar. 2010. Dissertação (Mestrado em Educação) - Faculdade de Educação, Universidade Federal do Rio Grande do Sul, Porto Alegre, 2010 .

PRADO, Patrícia Dias. "Agora ele é meu amigo": pesquisas com crianças, relações de idade, educação e culturas infantis. In: MARTINS FILHO, Altino José; PRADO, Patrícia Dias (org.). Das pesquisas com crianças à complexidade da infância. Campinas: Autores Associados, 2011. p. 107-128.

RHODEN, Sandra Mara. O sentido e o significado da notação musical das crianças. 2010. Dissertação (Mestrado em Educação) - Faculdade de Educação, Universidade Federal do Rio Grande do Sul, Porto Alegre, 2010.

RODRIGUES, Silvia Adriana; BORGES, Tammi Flavie Peres; SILVA, Anamaria Santana da. "Com olhos de criança": a metodologia de pesquisa com crianças pequenas no cenário brasileiro. Nuances: Estudos sobre Educação, Presidente Prudente, v. 25, n. 2, p. 270-290, maio/ago. 2014. 
RONCALE, Mariana Martins. Do rec ao play, e além: as gravações em uma oficina de música para crianças. 2017. Dissertação (Mestrado em Música) Centro de Artes, Universidade do Estado de Santa Catarina, Florianópolis, 2017.

SANTOS, Fátima Carneiro dos. A paisagem sonora, a criança e a cidade. 2006. Tese (Doutorado em Música) - Instituto de Artes, Universidade Estadual de Campinas, Campinas, 2006.

SARMENTO, Manuel José Jacinto. Conhecer a infância: os desenhos das crianças como produções simbólicas. In: MARTINS FILHO, Altino José; PRADO, Patrícia Dias (org.). Das pesquisas com crianças à complexidade da infância. Campinas: Autores Associados, 2011. p. 27-60.

VISNADI, Gabriela Flor. "A música que eu compus em grupo, eu tirei do coração": perspectivas das crianças sobre a composição musical na escola básica. 2013. Dissertação (Mestrado em Música) - Centro de Artes, Universidade do Estado de Santa Catarina, Florianópolis, 2013. 
Dhemy Fernando Vieira Brito é doutorando em Estudos da Criança, na especialidade de Infância, Cultura e Sociedade, pela Universidade do Minho (UMinho), em Braga, Portugal, mestre em Música pela Universidade do Estado de Santa Catarina (Udesc), bacharel em Canto pela Universidade Estadual de Maringá (UEM) e especialista em Educação Musical pela UEM. É membro do Centro de Investigação em Estudos da Criança - CIEC/UMinho. Regeu o Coro Infantil SESC Maringá e o Coro Infantil Cidadão do Amanhã (Santa Fé/PR). Como pesquisador e palestrante desenvolve projetos e oficinas voltados para as áreas de canto coral, canto coletivo e técnica vocal, por meio de atividades que promovam a visibilidade infantil. Lançou em 2020, pela Paco Editorial, o livro $O$ coro infantil e as crianças: por que e para quem elas cantam. https://orcid.org/0000-0002-2184-067X

Viviane Beineke é professora associada do Departamento de Música da Universidade do Estado de Santa Catarina (Udesc), atuando no curso de Licenciatura em Música, no Programa de Pós-Graduação em Música (PPGMUS) e no Mestrado Profissional em Artes (Prof-Artes). Bolsista de produtividade pelo CNPq (Conselho Nacional de Desenvolvimento Científico e Tecnológico). Líder do grupo de estudos e pesquisas Inventa Educação Musical e integrante do grupo MUSE - Música e Educação. Mestra e doutora em Música pela Universidade Federal do Rio Grande do Sul (UFRGS). Realizou pós-doutorado na Ludwig-Maximilians-Universität München (LMU), na Alemanha. Sua experiência profissional inclui também a atuação, durante dez anos, como professora de música em escola básica. Foi editora da revista Música na Educação Básica (MEB/Abem) nas gestões 2016-2017 e 2018-2019. Desenvolve pesquisas sobre a educação musical escolar, práticas musicais criativas, didática e metodologias do ensino de música e produção de material didático. https://orcid.org/0000-0003-2056-8149 